\title{
A rare cervical dystonia mimic in adults: congenital muscular torticollis (fibromatosis colli)
}

\author{
Hector Gonzalez-Usigli and Alberto J. Espay* \\ Department of Neurology, Gardner Family Center for Parkinson's Disease and Movement Disorders, University of Cincinnati School of Medicine, \\ Cincinnati, $\mathrm{OH}$, USA \\ *Correspondence: alberto.espay@uc.edu \\ Edited by: \\ Ryuji Kaji, Tokushima University Hospital, Japan \\ Reviewed by: \\ Ryuji Kaji, Tokushima University Hospital, Japan
}

Congenital muscular torticollis (CMT), also known as fibromatosis colli, is recognized as unilateral contracture and shortening of the sternocleidomastoid (SCM) muscle due to muscle atrophy and interstitial fibrosis, causing ipsilateral head tilt and turn (Do, 2006). Its frequency ranges from 0.3 to $2 \%$ in newborns with history of perinatal injury, but it is far less common in adults, who are often misdiagnosed as cervical dystonia (Patwardhan et al., 2011). In cases recognized during adulthood, subtle torticollis may have been overlooked since infancy or become apparent in the second decade of life or later (Brans et al., 1996). We report two cases recognized in adulthood initially misdiagnosed as cervical dystonia, whereby standard antidystonic treatments were unrewarding but SCM release proved beneficial.

\section{CASE REPORTS}

\section{CASE 1}

This 31-year-old woman exhibited a fixed left head tilt and turn with minor limitation of cervical range of motion since childhood. Her forceps-assisted birth by vaginal delivery was not associated with perinatal injuries. During childhood, she reported persistent head tilt to the left. She had headaches and back pain presumably from compensatory efforts at straightening her neck posture. There was no sensory trick or abnormal posturing of other body segments. Palpation of her neck musculature revealed a non-tender, taut fiber within the left SCM. She had limitation of right head tilt (see Video, Segment 1, Supplementary material; Figure 1A).

\section{CASE 2}

This 37-year-old woman became aware of right head turning and bilateral shoulder pain during her initial pregnancy, 9 years previously. A few years and two pregnancies later, she noted right head tilt and mild right turn with ipsilateral shoulder pain. Prominent tightening of the right SCM became apparent. There was no sensory trick or abnormal posturing of other body segments. Palpation of her neck musculature revealed a non-tender, taut fiber within the right SCM muscle (see Video, Segment 2, Supplementary material; Figures 1B,C).

Both patients worsened with botulinum toxin type A injections (onabotulinumtoxinA, BoNT-A increased over 3-4 sessions, respectively, to 150 units) into the affected SCM but experienced substantial relief of their torticollis and associated pain following partial myectomy of the anterior belly of the SCM muscle. Biopsy in both cases demonstrated fibrous transformation of skeletal muscle fibers (Figures 1D,E), pathognomonic of CMT.

\section{DISCUSSION}

CMT is a rare cause of pseudodystonia expressed as torticollis, whose recognition is important in order to avoid ineffective and potentially harmful antidystonic treatments. CMT is usually recognized in neonates as a circumscribed palpable mass confined to the SCM, affected unilaterally, which may gradually disappear between 4 and 8 months of age or be associated with other orthopedic abnormalities such as hip dysplasia or lower extremity abnormalities (Morrison and MacEwen, 1982). Its recognition in the second decade or later is unusual but possible when contracture and shortening of the SCM is mild and the head tilt toward the affected side is subtle. In addition to such tilt, however, several findings should increase the diagnostic

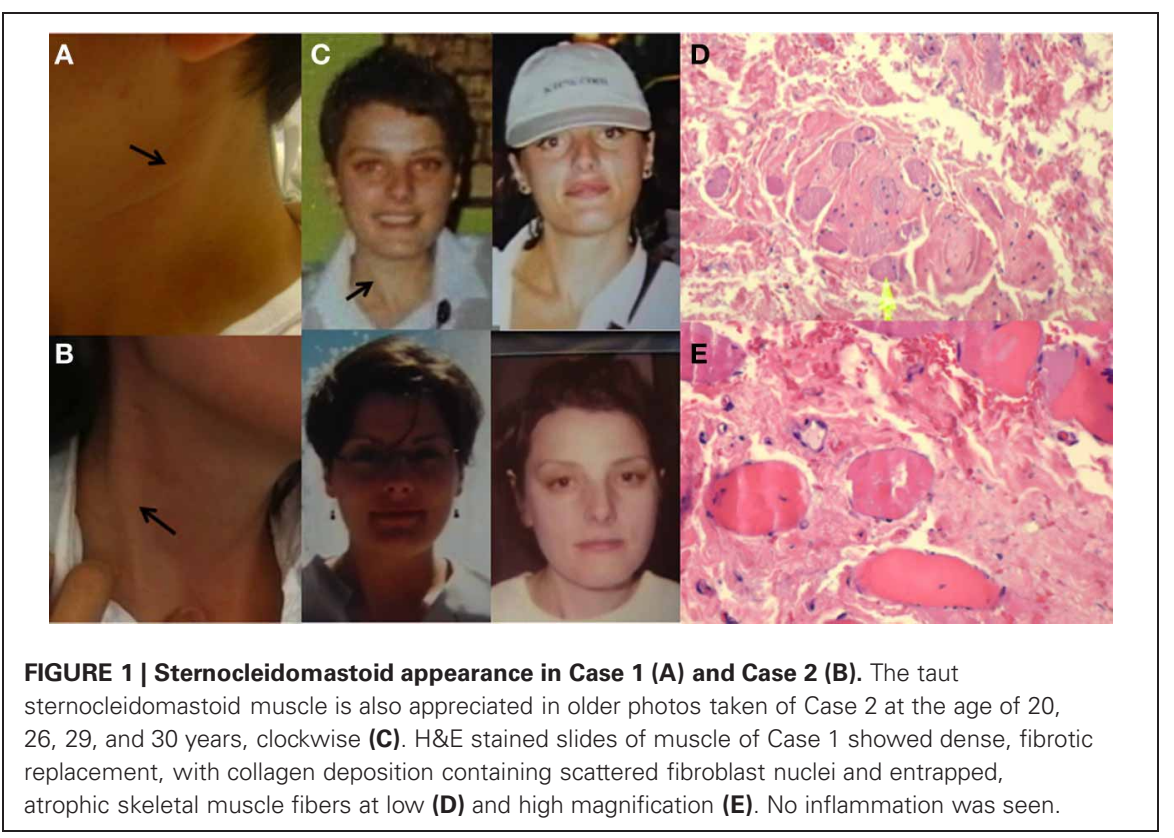


suspicion for this disorder, including the presence of a cord-like, fibrotic SCM muscle (as illustrated in the video of Case 2), the lack of a tremor component, and the absence of sensory tricks. CMT should be considered in the differential diagnosis of non-dystonic torticollis in young adults when the cervical posture is relatively fixed and a taut cord along the axis of the SCM can be palpated.

Although isolated successes have been reported with chemodenervation (Bouchard et al., 2010) the fibrotic replacement within the SCM makes BTX injections unlikely to provide sustained benefits (Collins and Jankovic, 2006). Surgical release, as shown by our cases, can be beneficial and justifies the clinical distinction of this disorder from cervical dystonia (Jones et al., 2012).

Besides CMT, other causes of pseudodystonic torticollis include focal myopathies, rotational atlantoaxial subluxation, posterior fossa tumors, congenital Klippel-Feil anomaly, syringomyelia, trochlear nerve palsy, and vestibular torticollis.

\section{ACKNOWLEDGMENTS}

Dr. Espay is supported by the K23 career development award (NIMH,
1K23MH092735); has received grant support from CleveMed/Great Lakes Neurotechnologies, Medtronic, Davis Phinney Foundation, and Michael J. Fox Foundation; personal compensation as a consultant/scientific advisory board member for Solvay, Abbott, Chelsea Therapeutics, TEVA, Impax, Solstice Neurosciences, and Eli Lilly; and honoraria from Novartis, the American Academy of Neurology, and the Movement Disorders Society. He serves as Assistant Editor of Movement Disorders, Frontiers in Movement Disorders, and on the editorial board of The European Neurological Journal.

\section{SUPPLEMENTARY MATERIAL}

The Supplementary Material for this article can be found online at: http://www. frontiersin.org/Movement_Disorders/10. 3389/fneur.2013.00006/full

\section{REFERENCES}

Bouchard, M., Chouinard, S., and Suchowersky, O. (2010). Adult cases of congenital muscular torticollis successfully treated with botulinum toxin. Mov. Disord. 25, 2453-2456.

Brans, J., Aramideh, M., Bosch, A., and Speelman, H. (1996). Late presentation of congenital muscular torticollis: a non-dystonic cause of torticollis. J. Neurol. 243, 354-356.

Collins, A., and Jankovic, J. (2006). Botulinum toxin injection for congenital muscular torticollis presenting in children and adults. Neurology 67, 1083-1085

Do, T. T. (2006). Congenital muscular torticollis: current concepts and review of treatment. Curr. Opin. Pediatr. 18, 26-29.

Jones, C. D., Nakhdjevani, A., and Lidder, S. (2012). Surgical management of idiopathic torticollis secondary to a fibrotic band. Orthop. Rev. (Pavia) 4:e27. doi: 10.4081/or.2012.e27

Morrison, D. L., and MacEwen, G. D. (1982). Congenital muscular torticollis: observations regarding clinical findings, associated conditions, and results of treatment. J. Pediatr. Orthop. 2, 500-505.

Patwardhan, S., Shyam, A. K., Sancheti, P., Arora, P., Nagda, T., and Naik, P. (2011). Adult presentation of congenital muscular torticollis: a series of 12 patients treated with a bipolar release of sternocleidomastoid and Z-lengthening. J. Bone Joint Surg. Br. 93, 828-832.

Received: 16 January 2013; accepted: 22 January 2013; published online: 12 February 2013.

Citation: Gonzalez-Usigli H and Espay AJ (2013) A rare cervical dystonia mimic in adults: congenital muscular torticollis (fibromatosis colli). Front. Neur. 4:6. doi: 10.3389/fneur.2013.00006

This article was submitted to Frontiers in Movement Disorders, a specialty of Frontiers in Neurology.

Copyright (c) 2013 Gonzalez-Usigli and Espay. This is an open-access article distributed under the terms of the Creative Commons Attribution License, which permits use, distribution and reproduction in other forums, provided the original authors and source are credited and subject to any copyright notices concerning any third-party graphics etc. 